\title{
Técnicas de Tratamento de Restrições aplicado em um Algoritmo Evolucionário Multiobjetivo para Repactuação de Outorgas em uma Bacia Hidrográfica
}

\section{Techniques for Handling Constraints applied on a Multiobjective Evolutionary Algorithm for Renegotiation of Concessions in a Watershed}

\author{
Fagner França da Costa ${ }^{l *}$; Érica Cristine Medeiros Nobre Machado ${ }^{2}$; Simone Nóbrega Ribeiro ${ }^{3}$; Wanessa Dunga de \\ Assis $^{4}$ e Wanessa Alves Martins ${ }^{5}$
}

\begin{abstract}
Resumo: A outorga é o instrumento de alocação de água entre os diversos usos da bacia hidrográfica, contudo, os critérios de determinação da vazão máxima outorgável são bastante restritivos, o que provoca descontentamentos e gera conflitos entre os usuários. Dessa forma, a outorga atua como fator limitante do quantitativo disponível a ser alocado, principalmente em bacias que já apontam para o esgotamento dos seus recursos hídricos outorgáveis. Algoritmos evolucionários multiobjetivo têm se destacado na otimização de problemas relacionados à gestão dos recursos hídricos. Neste trabalho utilizamos o algoritmo evolucionário multiobjetivo SPEA2 para alocação de água como suporte à negociação da repactuação da outorga em bacias hidrográficas com vazões outorgáveis insuficientes para a demanda. Diversas técnicas têm sido desenvolvidas para considerar as restrições específicas do problema e melhorar o desempenho de algoritmos evolucionários, neste trabalho analisamos o ganho de desempenho obtido pela introdução de algumas destas técnicas. Os resultados demonstram a importância da utilização das técnicas de tratamento das restrições, e a aplicabilidade da utilização do algoritmo evolucionário como sistema de suporte à decisão na gestão dos recursos hídricos.
\end{abstract}

Palavras-chave: Gestão dos recursos hídricos, otimização multiobjetivo, técnicas de tratamento das restrições.

\begin{abstract}
The grant is the instrument of water allocation between different uses of the basin, however, the criteria for determining the maximum flow grantable are quite restrictive, causing discontent and generates conflicts among users. In this way, the grant serves as a limiting factor of the quantitative available to allocate, particularly in basins that already point to the depletion of their water grant resources. Multiobjective evolutionary algorithms have excelled in optimizing problems related to water resources management. In this work we used the multiobjective evolutionary algorithm SPEA2 for water allocation to support of renegotiation of concession in watersheds with insufficient water grant resources. Several techniques have been developed to take the specific constraints of the problem and improve the performance of evolutionary algorithms, in this work we have analyzed the performance gain obtained by the introduction of some of these techniques. Its results show importance of using constraint handling techniques and the applicability of using the evolutionary algorithm as decision support in water resources management system.
\end{abstract}

Keywords: Water resources management, multiobjective optimization, constraint handling techniques.

\footnotetext{
*Autor para correspondência

Recebido em 02/09/2014 e aceito em 11/11/2014

${ }^{1}$ Graduado em Engenharia Ambiental - Universidade Federal de Campina Grande - UFCG/CCTA, Campus Pombal PB - Rua Jairo Vieira Feitosa, n 1770, Bairro dos Pereiros, CEP: 58.840.000. E-mail: fagnerengenheiroambiental@ gmail.com

${ }^{2}$ Engenheira Civil. Professor. Doutor. Unidade Acadêmica de Ciências e Tecnologia Ambiental, UFCG, Pombal, PB, E-mail:erica@ccta.ufcg.edu.br

${ }^{3}$ Graduada em Engenharia Ambiental - Universidade Federal de Campina Grande - UFCG/CCTA, Campus Pombal PB - Rua Jairo Vieira Feitosa, n 1770, Bairro dos Pereiros, CEP: 58.840.000. E-mail: simonenobrega2@gmail.com

${ }^{4}$ Graduada em Engenharia Ambiental - Universidade Federal de Campina Grande - UFCG/CCTA, Campus Pombal PB - Rua Jairo Vieira Feitosa, n 1770, Bairro dos Pereiros, CEP: 58.840.000.E-mail: w_dunga@hotmail.com

${ }^{5}$ Graduada em Engenharia Ambiental - Universidade Federal de Campina Grande - UFCG/CCTA, Campus Pombal PB - Rua Jairo Vieira Feitosa, n 1770, Bairro dos Pereiros, CEP: 58.840.000. E-mail: wanessa_ufcg@hotmail.com.br
} 


\section{INTRODUÇÃO}

Os conflitos pelo uso dos recursos hídricos podem ocorrer, dentre outros, entre usuários de mesma categoria, entre usos distintos, entre uso produtivo e gestão ambiental ou entre unidades diferentes (CORDEIRO NETO, 2005). Os conflitos gerados devido à escassez da água, denominados Conflitos de $1^{\mathrm{a}}$ ordem, são os mais comuns. Mas, existem ainda os conflitos resultantes de medidas e ações da gestão hídrica quando não bem planejadas ou executadas, denominados Conflitos de $2^{\mathrm{a}}$ ordem. Isso ocorre porque o processo de gestão hídrica é muito complexo, exigindo uma abordagem interdisciplinar e o envolvimento de diversos atores para o atendimento de múltiplos objetivos, entre eles, a minimização dos conflitos e a sustentabilidade dos recursos hídricos.

Para resolução de conflitos relacionados a recursos hídricos, LUND (2001 apud VIEIRA e RIBEIRO, 2005) enfatiza que o objetivo é reconciliar indivíduos ou grupos com objetivos e interesses conflitantes em relação à gestão hídrica, ou seja, há a necessidade de se obter uma solução politicamente aceita, através do consenso dos participantes.

No Brasil, uma potencial fonte de conflitos em bacias hidrográficas decorre dos critérios de determinação da vazão outorgável, que são bastante restritivos, provocando descontentamentos entre os usuários. Segundo estes critérios, como na maioria do tempo as vazões naturais nos rios ou regularizadas pelos reservatórios são superiores às vazões de referência e, como o que é outorgado é uma fração delas, o que ocorre, na pratica, são vazões bem maiores ao longo do ano (SILVA e MONTEIRO, 2004). Dessa forma, a outorga atua como fator limitante do quantitativo disponível a ser alocado principalmente em bacias que já apontam para o esgotamento dos seus recursos hídricos outorgaveis. Logo, em situações extremas de conflitos pode ser necessária a intervenção dos órgãos gestores e a negociação entre os usuários da bacia, no sentido de promover uma repactuação da outorga, como ocorreu na bacia do rio Piranhas-Açu, que culminou na definição do Marco Regulatório para a gestão do sistema Curema Açu, que estabelece os quantitativos a serem outorgados em função de critérios de eficiência préestabelecidos (BRAGA et al., 2004).

Logo, o objetivo deste trabalho foi analisar a viabilidade da incorporação de algumas dessas técnicas a um algoritmo evolucionário multiobjetivo utilizado para a repactuação de outorgas em bacias hidrográficas.

\section{MATERIAL E MÉTODOS}

\section{Área de estudo}

O trabalho foi realizado na bacia hidrográfica do rio Gramame localizada na região litorânea sul do Estado da Paraíba, e que é responsável por aproximadamente $70 \%$ do abastecimento da região metropolitana de João Pessoa, que está localizada fora dos limites geográficos da bacia. Para a realização deste estudo foi adotada a discretização da bacia em dez pontos de referência (Figura 1), cujas respectivas vazões de referências foram baseadas no Plano Diretor de Recursos Hídricos da Bacia (SEMARH, 2000).

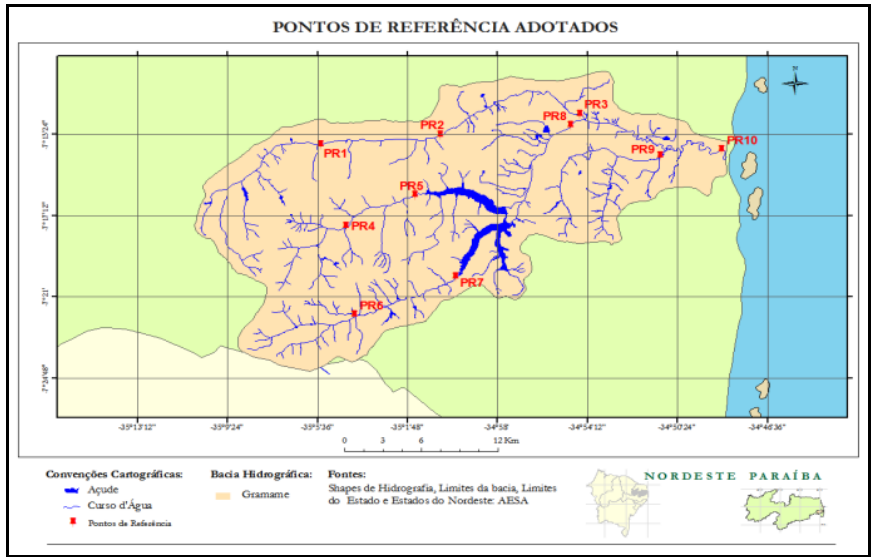

Figura 1 - Pontos de referência adotados.

Fonte: (MACHADO, 2011).

A Bacia Hidrográfica do rio Gramame pertence à Sub Bacia 39 da Região Hidrográfica Atlântico Nordeste Oriental, a qual abrange uma dezena de pequenas bacias costeiras, caracterizadas pela pequena extensão e vazão de seus corpos d'água (MACHADO, 2011). Ela está localizada na região litorânea sul do Estado da Paraíba, próxima à capital João Pessoa, entre as latitudes $7^{\circ} 11^{\prime}$ e $7^{\circ} 23^{\prime}$ Sul, e as longitudes $34^{\circ} 48^{\prime}$ e $35^{\circ} 10^{\prime}$ Oeste (NUNES, 2012), abrangendo os municípios de Alhandra, Conde, Crus do Espírito Santo, João Pessoa, Pedras de Fogo, Santa Rita e São Miguel de Taipu (MACHADO, 2003 apud NUNES, 2012).

Para a realização deste estudo foram considerados os pontos de cálculo definidos pelo Plano Diretor de Recursos Hídricos da Bacia (SEMARH, 2000), que para facilitar o desempenho do trabalho cada trecho analisado foi nomeado de pontos de referências (PR). Diante disso foram definidas dez regiões distintas, que são drenadas por um ponto de referência, cujas respectivas vazões de referências foram estabelecidas da seguinte maneira (MACHADO, 2011): 1) para os pontos de referência PR1, a PR7 e o PR9: vazão de referência estimada pelo Plano Diretor de Recursos Hídricos da bacia nos pontos de cálculo correspondentes; 2) para o PR8, a jusante do reservatório Gramame Mamuaba: vazão regularizada pelo reservatório com $98 \%$ de garantia estimada pelo Plano Diretor de Recursos Hídricos da bacia; 3) para o PR10, exutório da bacia: somatório das vazões de referência dos pontos de referência PR3, PR8 e PR9.

A vazão outorgada em cada ponto de referência foi definida como o valor máximo entre a vazão outorgável e o valor efetivamente outorgado pelo órgão gestor, sendo que, nos casos em que as demandas outorgadas atuais são superiores à outorgável, este excesso foi convertido em vazão adicional requerida, sendo distribuída a usuários característicos do trecho, e cujo valor alocado é o objeto de otimização do algoritmo proposto. Além disso, usuários significativos de irrigação apresentados no PDRH da bacia e não outorgados ainda, bem como prováveis novos usuários que podem vir a se instalar nos pontos de referência, também foram considerados como vazão adicional requerida, conforme critérios utilizados em MACHADO (2011). Para a vazão ecológica foi utilizado o valor equivalente a $10 \%$ da vazão de referência, que variava por trecho (Tabela 1).

Para determinação da vazão excedente a ser alocada considerou-se como dado de entrada a informação de 
previsões probabilísticas de precipitação para um ano de planejamento classificado como chuvoso, considerando-se as seguintes probabilidades de chuva: precipitação característica de ano seco (Ps) de 10\%; precipitação característica de ano normal (Pn) de 10\% e precipitação característica de ano chuvoso (Pch) de $80 \%$. A partir destas probabilidades, foi utilizado o método de reamostragem estatística proposto por CROLEY (1996 apud GALVÃO, 1999), o qual utilizou estas previsões categorizadas probabilísticas de precipitação para geração de uma série sintética, também de precipitação, com duração de 1.000 anos. Esta série sintética é obtida repetindose os registros da série histórica de precipitação de tal modo que a série sintética obedeça às probabilidades de ocorrência estabelecidas na previsão. Com a série sintética, assim como utilizado em MACHADO (2011), foi definido o valor previsto de vazão em cada ponto de referência da seguinte forma: toma-se a precipitação mensal prevista pela média aritmética da precipitação do referido mês de todos os anos da série sintética originada; divide-se esta precipitação mensal prevista pela precipitação mensal média histórica originando um coeficiente de afluência; multiplica-se o coeficiente de afluência mensal pela vazão mensal média histórica em cada ponto de referência para estimativa da vazão mensal prevista.

Considerou-se ainda no reservatório principal da bacia, o Gramame Mamuaba um modelo simplificado de operação, considerando como aporte as vazões remanescentes dos trechos a montantes e a precipitação prevista; e, como retiradas, a evaporação, a vazão outorgável do reservatório e o volume extravasado, quando ocorre.

Tabela 1- Vazões características dos pontos de referência adotados.

\begin{tabular}{ccccc}
\hline $\begin{array}{c}\text { Ponto de } \\
\text { referência }\end{array}$ & $\begin{array}{c}\text { Vazão de referência } \\
(\mathbf{l} / \mathbf{s})\end{array}$ & $\begin{array}{c}\text { Vazão outorgável } \\
(\mathbf{l} / \mathbf{s})\end{array}$ & $\begin{array}{c}\text { Vazão outorgada } \\
(\mathbf{l} / \mathbf{s})\end{array}$ & $\begin{array}{c}\text { Vazão Ecológica } \\
(\mathbf{l} / \mathbf{s})\end{array}$ \\
\hline PR1 & 150,0 & 135,0 & 6,0 & 15,0 \\
PR2 & 250,0 & 225,0 & 97,7 & 25,0 \\
PR3 & 580,0 & 522,0 & $1.865,7$ & 58,0 \\
PR4 & 150,0 & 135,0 & 8,2 & 15,0 \\
PR5 & 430,0 & 387,0 & 465,8 & 43,0 \\
PR6 & 55,0 & 49,5 & 89,2 & 5,5 \\
PR7 & 300,0 & 270,0 & $1.160,7$ & 30,0 \\
PR8 & $3.130,0$ & $2.817,0$ & $2.668,1$ & 313,0 \\
PR9 & 250,0 & 225,0 & 382,1 & 25,0 \\
PR10 & $3.960,0$ & $3.564,0$ & $4.926,0$ & 396,0 \\
\hline
\end{tabular}

\section{Método de otimização}

O método de otimização utilizado foi o Strentgh Pareto Evolutionary Algorithm 2 (SPEA2) (ZITZLER et al., 2001) e a solução de alocação foi representada, através de números reais, em uma matriz bidimensional (tempo $\mathrm{x}$ usuário) contendo $n$ colunas, uma para cada mês do período em análise, e nu linhas, uma para cada usuário (Figura 2).

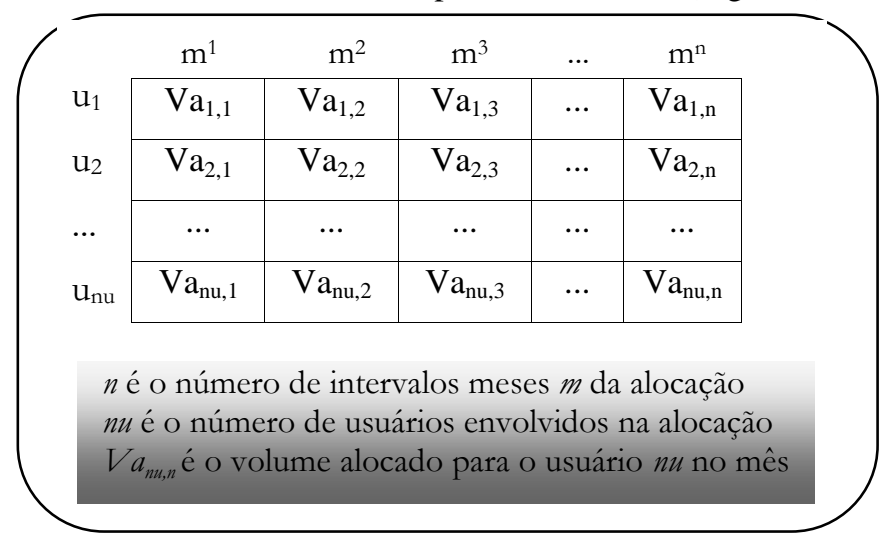

Figura 2 - Representação da solução.

Fonte: (MACHADO e GALVÃO, 2012).
Para geração de cada solução que compõe a população inicial, o volume disponível para alocação em cada trecho, uma vez conhecido, é distribuído através de um fator de proporção, conforme apresentado nas Equações 1 e 2.

$$
\begin{aligned}
& \mathrm{Va}_{\mathrm{um}}=\min \left(\mathrm{Vr}_{\mathrm{um}}, \mathrm{Pum}_{\mathrm{u}} \mathrm{q}_{\mathrm{e}} \cdot \mathrm{Vd}_{\mathrm{cm}}\right)
\end{aligned}
$$

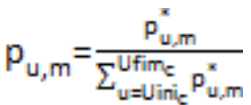

Onde:

$\mathrm{Va}_{\mathrm{u}, \mathrm{m}}$ é o volume alocado para o usuário u no mês m;

$\mathrm{Vr}_{\mathrm{u}, \mathrm{m}}$ é o volume requerido pelo usuário u no mês m;

$\mathrm{p}_{\mathrm{u}, \mathrm{m}}$ é a proporção de alocação do usuário u no mês m;

$\mathrm{q}_{\mathrm{c}}$ é o coeficiente de alocação para o ponto de referência c;

$\mathrm{Vd}_{\mathrm{c}, \mathrm{m}}$ é o volume disponível no ponto de referência c no mês m;

$\mathrm{p}_{\mathrm{u}, \mathrm{m}}$ é um número aleatório, contido no intervalo $[0,1]$ gerado para o usuário u no mês m;

Uini $_{\mathrm{c}}$ é usuário inicial do ponto de referência c;

Ufim $_{\mathrm{c}}$ é usuário final do ponto de referência c.

Foram consideradas duas funções objetivo de otimização. A Função objetivo 1, de ordem técnica, é uma função de maximização da satisfação do usuário, por tentar 
aproximar o volume alocado o tanto mais próximo quanto possível do requerido, ao mesmo tempo em que considera a eficiência do uso da água e prioridades diferentes de acordo com o tipo de uso da água, tal como apresentado na Equação 3.

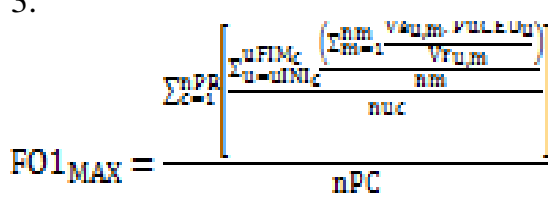

Onde: na bacia;

nPR é o número de pontos de referência de captação

nuc é o número de usuários vinculados ao ponto de referência de captação c;

$\mathrm{uNNI}_{\mathrm{c}}$ é o índice do usuário inicial do ponto de referência de captação c;

$\mathrm{uFIM}_{\mathrm{c}}$ é o índice do usuário final do ponto de referência de captação c;

$\mathrm{Va}_{\mathrm{u}, \mathrm{m}}$ é o volume adicional alocado para o usuário u no mês $\mathrm{m}\left[\mathrm{m}^{3}\right]$;

$\mathrm{Vr}_{\mathrm{u}, \mathrm{m}}$ é o volume adicional requerido pelo usuário u no mês $\mathrm{m}\left[\mathrm{m}^{3}\right]$;

$n \mathrm{~m}$ é número de meses do período da análise;

$\mathrm{P}_{\mathrm{u}}$ é o coeficiente de priorização do uso da água, valor variável de 0 a 1 , onde 1 consiste no uso mais prioritário e 0 ao uso menos prioritário. Sendo adotado neste trabalho: Abastecimento urbano igual a 1,00; Irrigação igual a 0,70 e o Industrial igual a 0,80 .

$\mathrm{CEU}_{\mathrm{u}}$ é o coeficiente de eficiência do uso da água pelo usuário, valor variável de 0 a 1 , onde 1 consiste no uso mais eficiente, sem perdas na utilização da água. Foram considerados os seguintes critérios: Irrigação dividida em três subgrupos: aspersão convencional móvel com seu valor sendo 0,70 , pivô central igual a 0,80 e aspersão com canhão gigante igual a 0,65; Abastecimento urbano igual a 1,00 e o Industrial igual a 0,50 .

A Função objetivo 2, de ordem ambiental, busca a minimização da emissão de poluentes, através da maximização da aproximação da concentração resultante da mistura (considerada como instantânea e completa) com a concentração máxima admissível (Equação 4).

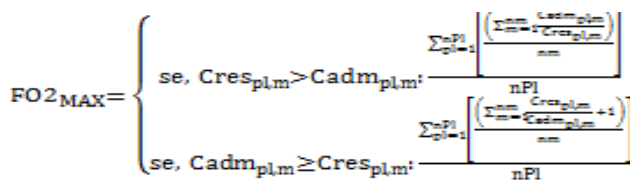

Onde:

nP1 é o número de pontos de referência de lançamento de efluentes na bacia hidrográfica;

Cres $_{\mathrm{pl}, \mathrm{m}}$ é a concentração resultante de $\mathrm{DBO}_{5}$ no ponto de referência de lançamento $\mathrm{pl}[\mathrm{mg} / \mathrm{l}]$;

Cadm $m_{p l, m}$ é a concentração admissível de $\mathrm{DBO}_{5}$ no ponto de referência de lançamento pl [mg/l], adorado em 10 $\mathrm{mg} / \mathrm{l}$ de $\mathrm{DBO}_{5}$ no ponto de referência 3, que é único trecho da bacia em que ocorre lançamento de efluentes.

\section{Descrição das restrições}

Neste estudo foram utilizadas como restrições as definidas em MACHADO (2011), as quais estão relacionadas à operação do reservatório, onde se concentram uma boa parte das outorgas de captação, e ao lançamento de poluentes em cursos d'água, e relacionadas a concentração de poluentes admissíveis no corpo hídrico, de modo a preservar a sua classe de enquadramento. Dessa forma, cada solução de otimização é avaliada em relação às restrições apresentadas, e, uma vez que alguma é violada, é acionado um alarme, denominando a solução como inviável. As restrições também são classificadas de acordo com o nível de severidade, que se refere a gravidade do dano causado. As restrições utilizadas e o nível de severidade de cada uma estão descritas a seguir:

- Sustentabilidade da operação no reservatório: Definida através da comparação entre o nível final e o inicial do reservatório. Soluções cujo nível final do reservatório seja menor do que $90 \%$ do inicial são consideradas inviáveis. Severidade baixa.

- Nível de reserva no reservatório: Manutenção de um nível de reserva no reservatório para absorver as incertezas envolvidas e garantir os usos prioritários. Soluções que violem esse volume de reserva (adotado como $40 \%$ do volume útil) são consideradas inviáveis. Severidade média.

- Concentração admissível dos poluentes: Para usuários de lançamento de efluentes, a carga lançada deve ser diluída na vazão disponível presente no trecho, sem alteração da concentração admissível. Soluções que violem a concentração admissível são consideradas inviáveis. Severidade alta.

\section{Alternativas de tratamento das restrições}

Duas formas gerais de considerar as restrições em métodos de otimizações podem ser definidas (CRAENEN et al., 2005): indiretamente, através da transformação da restrição em uma função objetivo ou da adição de uma função de penalidade; e diretamente, no qual as soluções inviáveis podem ser eliminadas, reparadas ou tratadas através de operadores especiais. Neste estudo, foram definidas alternativas para tratamento das restrições diretamente, as quais foram inseridas no método de otimização em trechos distintos: no operador de seleção dos indivíduos, no preenchimento da população externa, e nos operadores de reprodução.

\section{- Tratamento das restrições no operador de seleção}

O operador de seleção utilizado é o de torneio, no qual, tradicionalmente o campeão (indivíduo de melhor aptidão que é selecionado para reprodução) é definido apenas considerando os conceitos de dominância, nos quais são preferíveis os não dominados e, dentre estes, os de melhor aptidão.

Foi considerada neste trabalho, como alternativa, a incorporação do conceito de viabilidade no operador do torneio concomitantemente com os conceitos de dominância, da seguinte forma: 1) entre um indivíduo viável e um inviável, seleciona-se o indivíduo viável; 2) entre dois indivíduos viáveis, seleciona-se aquele de menor aptidão; e 3 ) entre dois indivíduos inviáveis, seleciona-se aquele em que o ponto de falha (mês de violação da primeira restrição) está 
mais próximo do final do horizonte de operação e, caso ocorra empate, seleciona-se o indivíduo que violou o alarme de menor severidade; persistindo o empate, seleciona-se o indivíduo de menor valor de aptidão.

- Tratamento das restrições no preenchimento da população externa

O preenchimento da população conforme tradicionalmente realizado no SPEA2 considera apenas os conceitos de dominância, ou seja, selecionam-se em cada iteração do algoritmo os indivíduos não dominados para compor a população externa, de onde serão selecionados os indivíduos para reprodução. Neste trabalho foi avaliado também, como alternativa, um procedimento de preenchimento que prioriza os indivíduos viáveis (aquela em que não ocorre nenhuma violação das restrições) em relação aos inviáveis (onde ocorre alguma violação nas restrições) e, dentre os inviáveis, prioriza aqueles em que a violação da restrição é de menor severidade ou ocorre mais tardiamente.

Nessa alternativa, ao invés de selecionar as soluções não-dominadas da população para compor a população externa, selecionam-se as soluções viáveis não-dominadas conforme sugerido por MACHADO (2006).

\section{reprodução}

- Tratamento das restrições nos operadores de

Foram utilizados tanto operadores tradicionais da literatura quanto operadores denominados direcionados, por considerar o tipo e severidade da violação da restrição violada em cada indivíduo infactível, adaptados de BRASILEIRO (2005) e MACHADO (2006), que desenvolveram operadores semelhantes para variáveis binárias na otimização da operação de redes de escoamento de petróleo.

A sequência de utilização dos operadores no processo de reprodução está apresentada na Figura 3, sendo que, como o objetivo é verificar a melhora nos resultados da otimização em relação as alternativas de incorporação das restrições incorporadas, em alguns experimentos foram utilizados apenas os operadores tradicionais (Crossover Média - CM seguido da Mutação Uniforme - MU), em outros apenas os operadores direcionados (Crossover Direcionado - CD em paralelo com a Mutação Direcionada - MD) e, em outros, combinações destes operadores.

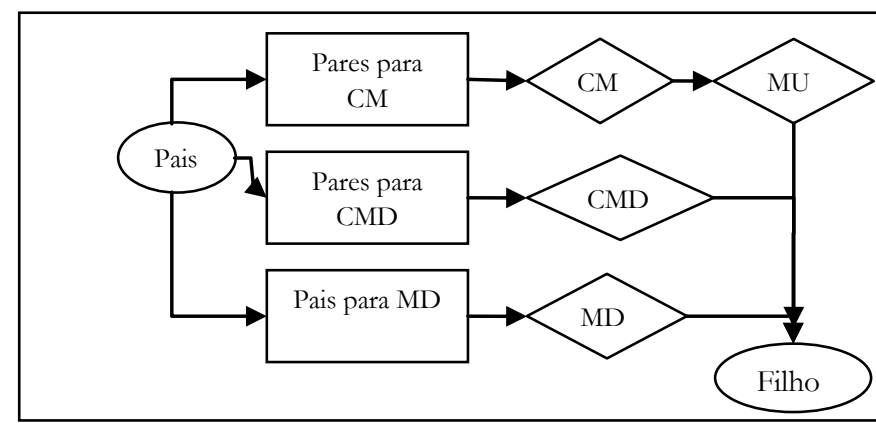

Figura 3 - Sequência de aplicação dos operadores de reprodução.

Fonte: (MACHADO, 2011).

\section{Incorporação de conhecimento no método de otimização}

As principais adaptações incorporadas ao método de otimização foi a consideração do conceito de viabilidade das soluções no operador de seleção por torneio e nos operadores de reprodução. Dessa forma, as soluções foram categorizadas em viáveis e inviáveis, sendo que as inviáveis são avaliadas, além das funções objetivo, pelas informações do tipo e severidade da restrição violada.

$\mathrm{Na}$ seleção por torneio o campeão (indivíduo de melhor aptidão) é definido considerando concomitantemente os conceitos de viabilidade e de dominância, da seguinte forma: 1) entre um indivíduo viável e um inviável, selecionase o indivíduo viável; 2) entre dois indivíduos viáveis, seleciona-se aquele de menor Fitness; e 3) entre dois indivíduos inviáveis, seleciona-se aquele em que o ponto de falha está mais próximo do final do horizonte de operação e, caso ocorra empate, seleciona-se o indivíduo que violou o alarme de menor severidade; persistindo o empate, selecionase o indivíduo de menor valor de Fitness.

Em relação aos operadores de reprodução, foram avaliados juntamente com operadores tradicionais da literatura, operadores denominados direcionados, por considerar o tipo e severidade da violação da restrição violada em cada indivíduo infactível, adaptados de BRASILEIRO (2005) e MACHADO (2006), que desenvolveram operadores semelhantes para variáveis binárias na otimização da operação de redes de escoamento de petróleo.

No operador Crossover média (DAVIS, 1991 apud LACERDA e CARVALHO, 1999), cada gene do filho gerado é obtido através da média aritmética dos respectivos genes dos indivíduos pais. Ressalte-se que esta operação apenas será aplicada caso seja satisfeita a probabilidade definida para este operador, caso contrário, o filho da reprodução será tomado como uma réplica do melhor entre os dois pais, considerandose os mesmos critérios do operador por torneio na definição do melhor.

Já no Crossover média direcionado, em cada par de pais submetido a este operador, é observada a viabilidade e o ponto de falha mais prematuro entre os dois. Se os dois pais forem viáveis ou se a probabilidade de aplicação deste operador não for satisfeita, nenhuma operação é realizada, sendo o indivíduo filho tomado como uma réplica do melhor indivíduo pai. Por outro lado, quando a probabilidade é atendida, o volume alocado do indivíduo filho até o instante anterior ao ponto de falha mais prematuro é tomado como uma réplica do melhor indivíduo pai, instante a partir do qual o volume alocado é tomado pela média aritmética dos respectivos valores dos indivíduos pais, tal como, crossover média.

O operador de Mutação uniforme (LACERDA e CARVALHO, 1999) age também restrito a uma probabilidade de aplicação, avaliado em cada trecho e mês da bacia hidrográfica, sendo que, quando a mesma não é satisfeita, os genes do indivíduo filho referentes aos volumes alocados naquele trecho/mês permanecem inalterados. Caso contrário os genes do indivíduo filho serão substituídos pelos genes correspondentes de um indivíduo gerado aleatoriamente, da mesma forma como descrito na geração de indivíduos para preenchimento da população inicial.

Já no operador de Mutação direcionada, por sua vez, quando a probabilidade de aplicação não é satisfeita ou quando o indivíduo filho não viola nenhuma restrição, 
indivíduo filho é tomado como uma réplica do indivíduo pai. Caso contrário, é observado o ponto de falha e o tipo de restrição violada, efetuando ações de reparo específicas para cada restrição, ou seja, alterando o volume alocado, aumentando-o ou diminuindo-o, em intervalos de tempo específicos, no intuito de eliminar a violação da restrição.

\section{Métricas de avaliação do desempenho}

Tais métricas foram definidas com o propósito de comparar os resultados do algoritmo evolucionário tradicional com os resultados deste algoritmo após a incorporação gradual das técnicas de tratamento das restrições, e foram selecionadas de acordo com o que se deseja atingir para que o conjunto de soluções otimizadas encontrado seja considerado satisfatório: proximidade da fronteira Pareto e diversidade das soluções.

A Fronteira Pareto é o conjunto formado por todas as soluções não dominadas do espaço de busca das soluções factíveis do problema, onde se entende por soluções não dominadas "aquelas em que entre si, só é possível melhorar um objetivo causando um detrimento simultâneo em outro, e são melhores que as demais em pelo menos um objetivo" (COELLO et al., 2002). Para avaliar a proximidade das soluções otimizadas da fronteira Pareto, esta deve ser previamente conhecida através de uma enumeração exaustiva, método enumerativo que consiste em realizar uma varredura completa de todas as soluções possíveis do espaço de busca e, dessa forma, definir as melhores soluções possíveis, ótimo global, dispostos na fronteira Pareto. Apesar da simplicidade, esse método não é recomendável para otimizações de problemas que possuem espaços de busca muito grande, pois podem requerer um tempo inexequíivel para avaliar todas as soluções (MICHALEWICZ e FOGEL, 2002).

Diante disso, e com o objetivo de caracterizar o espaço de busca, foi realizada neste estudo uma enumeração semi exaustiva, com propósito de avaliar as soluções e definir uma fronteira próxima à de Pareto. Logo, foram dispostas no espaço de busca as funções objetivo de 50.000 soluções geradas aleatoriamente e, dentre tais soluções, foram definidas duas Fronteiras Pareto: aquela definida apenas entre os indivíduos viáveis e aquela definida apenas entre os indivíduos inviáveis.

Dessa forma, a métrica de proximidade da fronteira Pareto foi avaliada graficamente, através da disposição das soluções otimizadas de melhor aptidão, obtidas em cada alternativa, no espaço de busca que contém as fronteira Pareto de soluções viáveis e a Fronteira Pareto de soluções inviáveis obtidas pela enumeração semi exaustiva de 50.000 soluções geradas aleatoriamente, sendo que, são preferíveis as soluções que mais se aproximarem da fronteira Pareto de soluções viáveis.

Ainda para avaliar a proximidade das soluções com a fronteira Pareto foi utilizada uma métrica de convergência definida pelo cômputo da proporção das soluções não dominadas encontradas em uma otimização que dominam as soluções não dominadas encontradas em outra otimização, a qual se caracteriza como uma métrica de análise binária. Com isso, tendo cada otimização fornecido um conjunto de soluções de compromisso (não dominadas viáveis) para o problema, todas essas soluções serão armazenadas em um único conjunto e, desse conjunto, serão extraídas apenas as soluções não dominadas. Portanto, a alternativa que tiver encontrado o maior número dessas soluções não dominadas do conjunto total será considerado de melhor desempenho nesta métrica.

Já para a diversidade, utilizou-se a métrica SCHOTT (1995 apud DEB, 2001), a qual é baseada no espaçamento entre as soluções, que calcula a distância relativa média entre soluções consecutivas no conjunto não dominado obtido, dada pela Equação 5. Quando as soluções são uniformemente espaçadas, essa medida de diversidade será igual a zero. Tal métrica foi considerada para avaliar o atendimento da meta de diversidade, ou seja, o cenário cujo conjunto de soluções viáveis não dominadas obtiver o menor valor desta métrica será considerado de melhor desempenho com respeito à diversidade entre as soluções encontradas.

$M S=\sqrt{\frac{1}{\left|P V^{*}\right|} \cdot \sum_{\ell=1}^{\left|P V^{*}\right|}\left(m d_{\ell}-\overline{m d}\right)^{2}}$

Onde:

$M S$ é o valor da métrica de espaçamento;

$P V$ *é o conjunto de soluções não-dominadas viáveis;

$m d_{\ell}$ é a medida de distância do indivíduo $\ell$, dada pelo mínimo valor da soma da diferença absoluta dos valores das funções-objetivo entre a solução $\ell$ e qualquer outra solução do conjunto $P V^{*}$;

$\overline{m d}$ é a média das medidas de distâncias de todos os indivíduos do conjunto $P V *$.

\section{Descrição dos experimentos}

Em um problema de otimização multiobjetivo, duas metas devem ser atingidas para que o conjunto de soluções não-dominadas encontrado seja considerado satisfatório: que suas soluções estejam tão próximas quanto possível da Fronteira de Pareto e que suas soluções sejam tão diversificadas quanto possível. A primeira meta é similar à desejada na otimização de um único objetivo, a qual se dedica a encontrar o ótimo global do sistema, enquanto que a segunda é específica para otimização multiobjetivo, e é requerida para que seja garantida a diversidade de soluções de compromisso entre todos os objetivos (MACHADO, 2011).

A análise do desempenho foi realizada em quatro metodologias distintas, alternou-se entre o método de otimização SPEA2 conforme originalmente definido e utilizando os operadores tradicionais de seleção e reprodução e as alternativas de tratamento das restrições incorporadas neste método, as quais consideram a viabilidade dos indivíduos. A descrição das metodologias está apresentada na Tabela 2.

Em todas as metodologias descritas cada execução da otimização foi realizada cinco vezes, de modo a definir os valores das métricas de otimização com os valores médios de cada execução. Além disso, foram mantidos invariáveis os 
parâmetros de controle do algoritmo evolucionário, os quais foram: tamanho da população (300 indivíduos); dimensão da população externa $(50 \%$ da população); probabilidade de crossover médio (CM 90\%); probabilidade de crossover médio direcionado (CMD 90\%); probabilidade de mutação direcionada (MD 5\%) e o critério de parada (500 gerações).

Tabela 2 - Descrição dos cenários.

\begin{tabular}{cccc} 
Metodologia & $\begin{array}{c}\text { Preenchimento da população } \\
\text { externa }\end{array}$ & Operador de seleção por torneio & $\begin{array}{c}\text { Operadores de } \\
\text { reprodução }\end{array}$ \\
\hline 1 & Sem considerar a viabilidade & Sem considerar a viabilidade & $50 \%$ CMD e 50\% MD \\
2 & Considerando a viabilidade & Considerando a viabilidade & $50 \%$ CMD e 50\% MD \\
3 & Considerando a viabilidade & Considerando a viabilidade & $40 \% \mathrm{CMD}, 20 \% \mathrm{MD}$ e $40 \%$ \\
4 & Sem considerar a viabilidade & Sem considerar a viabilidade & $\mathrm{CM}$ \\
\hline
\end{tabular}

\section{RESULTADOS E DISCUSSÃO}

Diante dos resultados da análise do espaço de busca resultante da enumeração semi exaustiva foi constatado um cenário onde 99,97\% das soluções são Dominadas Inviáveis, e apenas 0,03\% são Não Dominadas Inviáveis. Vale salientar que, ao final da otimização o algoritmo evolucionário não encontrou nenhuma solução viável. Uma possível causa para este acontecimento pode ter sido pelo fato de que a vazão disponível, que é a vazão outorgável, é muita restritiva e, em alguns trechos possuem valores muito inferiores aos valores requeridos pelos usuários. RODRIGUES et al., 2004 , utilizando AGs como solução para problemas de planejamento florestal, constatou dentre os métodos utilizados, que os melhores resultados encontrado pelos autores foram observados quando se utilizou os métodos de seleção de Boltzmann e escalonamento, com tamanhos de população variando entre 75 e 100 indivíduos. Vale salientar que o tipo de crossover não afetou a eficácia do AG.

Observa-se que os valores da Função objetivo 1 variam de 0,10 a 0,28. Já a Função objetivo 2, variou de 0,10 a 1,64. Os valores da função objetivo 1 diz respeito ao volume alocado, entre os usuários. Percebe-se que de forma geral os valores alocados, foram bem inferiores aos requeridos pelos usuários da bacia. Por outro lado os valores da função objetivo 2 tratam da concentração admissível de $\mathrm{DBO}_{5}$, onde se constata que boa parte das soluções estão concentradas abaixo do valor 1 , ou seja, cuja as concentrações do corpo receptor estão acima da máxima permitida (Figura 4).

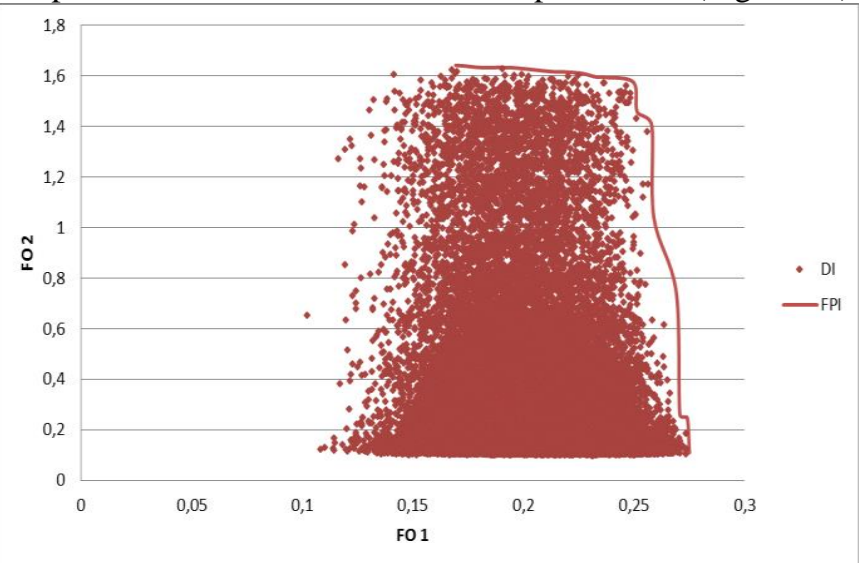

Figura 4 - Caracterização do espaço de busca e Fronteira Pareto $(\mathrm{DI}=$ Dominada Inviável e FPI $=$ Fronteira Pareto Inviável).
Para determinação de uma solução ótima, a utilização de técnicas de otimização alternativamente à otimização por Busca Exaustiva torna-se conveniente quando analisados problemas muito complexos, uma vez que poderiam demandar tempos de processamento inviáveis para a determinação de uma solução ótima global. No entanto, quando da análise de sistemas muito complexos, como em bacias com múltiplos lançamentos e captações, com disposição de cargas difusas e com diferentes condições de assimilação dos efluentes ao longo do sistema hídrico, sua aplicação pode ser comprometida devido ao fato de que seu método de busca iterativo é baseado em soluções pretéritas (VALORY et al., 2013).

BARBALHO, F. D. e FORMIGA, K. T. M. (2009) utilizando algoritmos genéticos na operação de sistemas de reservatórios, constatou que a utilização de Algoritmos Genéticos, associado a um sistema de simulação, em que a flexibilidade do modelo na incorporação de outras funções objetivas torna a rotina aplicável em outros modelos que simulam a operação de reservatórios.

A Tabela 3 mostra os valores médios obtidos para as métricas de convergência e diversidade. E, a Figura 6, a disposição no espaço de busca das soluções otimizadas em cada cenário.

Observa-se que o cenário 3 foi a que apresentou melhor resultado, tendo em vista que, a mesma ao final da otimização obteve o maior número de soluções dominadas inviáveis do conjunto global (Métrica de convergência), por outro lado, obteve o segundo maior valor da métrica de diversidade. Vale salientar que, a metodologia cujo conjunto de soluções viáveis não dominadas obtiver o menor valor para a métrica de diversidade, será considerada de melhor desempenho com respeito à diversidade entre as soluções encontradas (MACHADO, 2006; MACHADO, 2011). Tal metodologia considera a viabilidade apenas nos operadores de reprodução, preenchendo a população externa e utilizando o operador de torneio na forma tradicional, de onde se destaca a utilidade da incorporação de conhecimento nos operadores de reprodução a é caracterizada pelo uso concomitante dos operadores tradicionais com os operadores direcionados de onde se conclui que, a utilização da viabilidade da solução apenas no operador de torneio nos cenários 2 e 3 não foram suficiente para progressão da otimização (Tabela 3).

Tabela 3 - Valores da métrica de convergência e diversidade. 


\begin{tabular}{lcc} 
Metodologia & $\begin{array}{c}\text { Métrica da } \\
\text { Convergência } \\
\text { (MC) }\end{array}$ & $\begin{array}{c}\text { Métrica de } \\
\text { Diversidade (MS) }\end{array}$ \\
\hline
\end{tabular}

1

(1)

2

3

4
6

1

11

1
0,039282492

0,070783906

0,107386903
0,028644284

Verifica-se ainda na Figura 5 que, de forma geral, em relação ao critério eficácia da otimização, com exceção do cenário 4, os demais cenários conseguiram atingir esta fronteira (que ultrapassou a Fronteira Pareto de soluções não dominadas inviáveis). Ou seja, a metodologia 4, que não considera a viabilidade das soluções nem nos operadores de reprodução nem na evolução do algoritmo, não obteve êxito na otimização no critério de eficácia.

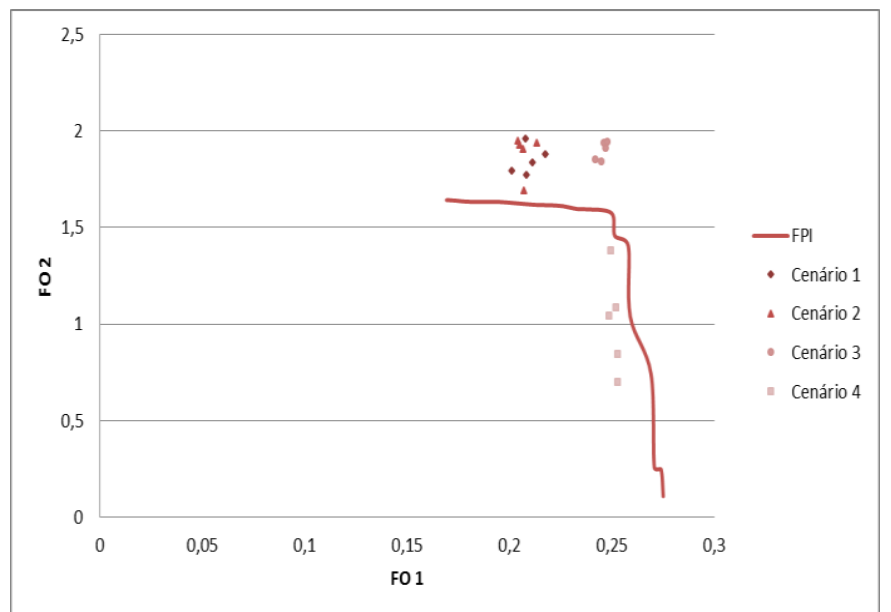

Figura 5 - Disposição no espaço de busca das soluções otimizadas (FPI= Fronteira Pareto Inviável)

\section{CONCLUSÕES}

Em todas as formas de tratamento das restrições consideradas nas metodologias 1 a 3 é priorizada a técnica de exploitation, que consiste em utilizar as informações presentes nas soluções já encontradas para guiar a busca, neste caso, a informação da viabilidade da solução. Diferentemente do que ocorre na execução do algoritmo da forma tradicional, como na metodologia 4, onde é permitida uma exploração mais ampla do espaço de busca, ou seja, é priorizada a técnica de exploration. Concluiu-se que os melhores resultados foram obtidos nas alternativas que utilizam os operadores denominados direcionados como única forma de consideração da viabilidade, ou seja, tal como demonstrado por MACHADO (2006), o equilíbrio entre estas duas técnicas contribuem para o sucesso de uma otimização, caracterizado pela proximidade da solução otimizada com a Fronteira Pareto de soluções viáveis e pela diversidade das soluções encontradas.
Ademais, em relação aos parâmetros de controle do algoritmo evolucionários, foram obtidos valores em concordância com os sugeridos pela literatura, sendo que, verifica-se uma semelhança considerável entre todos os resultados de cada metodologia avaliada para este fim, o que indica que, ou tais parâmetros não provocam muito impacto no desempenho da otimização, ou precisam ser mais bem avaliados de modo a destacar aquele conjunto de parâmetros de melhor desempenho.

\section{REFERÊNCIAS BIBLIOGRÁFICAS}

BARBALHO, F. D. e FORMIGA, K. T. M. Aplicação de Algoritmos Genéticos na Otimização da Operação de Sistemas de Reservatórios. Anais do XVIII Simpósio Brasileiro de Recursos Hídricos, Campo Grande - MS, 2009.

BRAGA, C. F. C.; DINIZ, L. S.; GARJULLI, R.; SILVA, L. M. C.; NOGUEIRA, G. M. F.; NASCIMENTO Jr., C. N. S.; MEDEIROS, S. D.; RÊGO, M. F. F. Construção do marco regulatório do sistema Curema Açu. Anais do VII Simpósio de Recursos Hídricos do Nordeste, São Luís - MA, 2004.

BRASILEIRO, E. Um algoritmo genético para otimização do controle em tempo real de redes de escoamento de petróleo. Dissertação - Programa de Pós Graduação em Ciência da Computação da Universidade Federal de Campina Grande, Campina Grande-PB, 2005.

COELLO, C.; VELDHUIZEN, D.; LAMONT, G. Evolutionary Algorithms for Solving Multi-Objective Problems. Kluwer academic, Plenum publishers, 576p, 2002.

CORDEIRO, N. O. Conflitos no uso da água. I curso de especialização em gerenciamento socioambiental. UFPE/CHESF, Recife-PE, 2005.

CRAENEN, B.; EIBEN, A.; HEMERT, J. Comparing Evolutionary Algorithms on Binary Constraint Satisfaction Problems. In IEEE Transactions on Evolutionary Computation, Vol. 7, No. 5, 2005.

DEB, K. Multi-objective optimization using evolutionary algorithms. John Wiley e Sons, Ltd., Chichester (England), 518p, 2001.

GALVÃO, C. O. Aplicabilidade em recursos hídricos da previsão de precipitação de longo prazo no Nordeste do Brasil. Tese - Programa de Pós-Graduação em Engenharia de Recursos Hídricos e Saneamento Ambiental, Universidade Federal do Rio Grande do Sul. Porto Alegre - RS, 1999.

LACERDA, E.; CARVALHO, A. Introdução aos algoritmos genéticos. In: GALVÃO, C.; VALENÇA, M. (organizadores), Sistemas inteligentes: Aplicações a recursos hídricos e ciências ambientais. ABRH, editora UFRGS, Porto Alegre, p. 99 - 150, 1999. 
MACHADO, E. C. M. N.; GALVÃO, C. O. Alocação Qualiquantitativa de Águas em Bacias Hidrográficas: Metodologia Multiobjetivo Inserida no Contexto da Gestão dos Recursos Hídricos. Revista Brasileira de Recursos Hídricos. Vol. 17, No. 2, Abr/Jun, p. 213-227, 2012.

MACHADO, E. C. M. N. Metodologia multiobjetivo para alocação da vazão excedente em bacias hidrográficas. Campina Grande: UFCG. 131f. Tese - Programa de Pós Graduação em Recursos Naturais da Universidade Federal de Campina Grande, 2011.

MACHADO, E. C. M. N. Operação de redes de escoamento de petróleo utilizando algoritmo genético multiobjetivo. Campina Grande: UFCG. 161f. Dissertação - Programa de Pós Graduação em Engenharia Civil e Ambiental da Universidade Federal de Campina Grande, 2006.

MICHALEWICZ, Z; FOGEL, D. How to solve it: Modern Heuristics. Springer, Berlim, 460p, 2002.

NUNES, E. M. Poluição Industrial da Bacia do Rio Gramame e Conflito Socioambiental: Análise da Complexidade a Partir dos Atores, Impactos e Perspectivas. João Pessoa: UFPB. 171 f. Dissertação Programa de Pós Graduação em Desenvolvimento e Meio Ambiente, Universidade Federal da Paraíba, 2012.

RODRIGUES, F. L. et al. Metaheurística algoritmo genético para solução de problemas de planejamento florestal com restrições de integridade. Revista Árvore. Vol. 28, No. 2, p. 233-245, 2004.

SEMARH. Plano diretor de recursos hídricos da Bacia do rio Gramame. Governo do Estado da Paraíba, Secretaria Extraordinária do Meio Ambiente, dos Recursos Hídricos e Minerais - SEMARH, 2000.

SILVA, L. M. C.; MONTEIRO, R. A. Outorga de direito de uso de recursos hídricos: Uma das possíveis abordagens. In: Machado, C. J. S. (Org.) - Gestão de Águas Doces. 1 ed. Rio de Janeiro: Interciência, Vol. 1, p. $135-178,2004$.

VALORY, J. P. L.; FRAUCHES, V. G. L.; REIS, J. A. T. e MENDONÇA, A. S. F. Aplicação combinada de técnicas de otimização e de modelagem de água no processo de seleção de sistemas de tratamento de esgotos. Anais do XX Simpósio Brasileiro de Recursos Hídricos, Bento Gonçalves - RS, 2013. 1 PEN DRIVE.

VIEIRA, Z. M.; RIBEIRO, M. M. Análise de conflitos: Apoio à decisão no gerenciamento d demanda urbana de água. Revista brasileira de recursos hídricos, Vol. 10, $\mathrm{N}^{\mathrm{o}} .3,2005$.

ZITZLER, E.; LAUMANNS, M.; THIELE, L. SPEA2: Improving the Strength Pareto Evolutionary
Algorithm. Technical report 103, Zürich, Switzerland: Computer Engineering and Network Laboratory (TIK), Swiss Federal Institute of Technology (ETH), 2001. 